\title{
CIRCULARIDADE E FUNDAMENTO NA METAFÍSICA DE DESCARTES
}

Circulatity and background in metaphysics of Descartes

João Evangelista Fernandes*

Resumo: A questão de um possível círculo vicioso na metafísica de Descartes foi apontada por seus contemporâneos até mesmo antes da publicação das Meditações Metafísicas. Ao que o filósofo respondeu recorrendo ao argumento da lembrança, o qual foi interpretado erroneamente como um recurso mnemônico e, portanto, supondo uma resposta insatisfatória do filósofo às objeções que lhe foram feitas. Pretendemos, por meio deste artigo, uma exposição da interpretação desta resposta de Descartes, feita por Jean-Marrie Beyssade, onde ele defende uma dupla fundamentação para a metafísica de Descartes em que o problema do círculo vicioso encontra uma resposta.

Palavras-chave: Cogito. Deus. Substância. Fundamento. Círculo.

\begin{abstract}
The issue of a possible vicious circle metaphysics of Descartes was reported by his contemporaries even before publication of the Metaphysical Meditations. To which the philosopher replied argument using the souvenir, which was misinterpreted as a mnemonic device and thus assuming an unsatisfactory response from the philosopher to the objections that have been made. We intend, through this article, an exhibition of this response interpretation of Descartes, made by Jean-Marrie Beyssade, where he advocates a dual basis for the metaphysics of Descartes in which the problem of the vicious circle finds an answer.
\end{abstract}

Keywords: Cogito. God. Substance. Background. Circle.

\footnotetext{
* Mestrando do Programa de Pós-graduação em Filosofia pela Universidade Estadual de Maringá (UEM). Bolsista CAPES. Contato: je_fernandes10@ hotmail.com
}

\begin{tabular}{|c|c|c|c|c|c|}
\hline intuitio & $\begin{array}{c}\text { ISSN } \\
1983-4012\end{array}$ & Porto Alegre & Vol.7 $-\mathrm{N}^{\mathrm{o}} .2$ & $\begin{array}{c}\text { Novembro } \\
2014\end{array}$ & p. 122-133 \\
\hline
\end{tabular}


Acreditamos que se há um tema em que a problemática do fundamento na metafísica de Descartes possa ser exposta de maneira objetiva e com certa densidade, seja o problema do círculo cartesiano, embora, como nos diz Jean-Marie Beyssade, esta questão "é inseparável da metafísica cartesiana como um todo, e, como ela foi proposta efetivamente a Descartes por seus contemporâneos, e porque ele mesmo a respondeu, é preciso, para tratá-la, rever o conjunto do corpus cartesiano"1. Ou seja, o problema do círculo cartesiano torna possível uma compreensão da metafísica cartesiana, no entanto, está relacionada a toda sua obra, o que, para uma abordagem profunda do tema, exigiria um estudo mais detalhado do autor em questão e, como não dispomos de tempo e nem é esse o nosso objetivo, adiantamos que nos ateremos a trechos das Meditações Metafísicas e das Quartas objeções e Quartas Respostas ${ }^{2}$, donde procuraremos extrair, a partir da interpretação da resposta ao problema do círculo cartesiano oferecida por Beyssade em seu artigo Sobre o Círculo Cartesiano, uma conclusão do que seja o fundamento da metafísica, proposto por Descartes.

O problema do círculo cartesiano consiste em que, segundo seus contemporâneos, assim como boa parte de seus futuros leitores, Descartes incorre em um círculo vicioso, na medida em que afirma que podemos "determinar como regra geral que todas as coisas que concebemos bastante clara e distintamente são verdadeiras"3. Por outro lado, algo só pode ser considerado verdadeiramente claro e distinto depois da prova da existência de Deus, na qual se chega mediante a regra geral. É o que formulou Arnauld no seguinte trecho Quartas Objeções:

Eu ainda tenho um escrúpulo que é o de saber como ele pode se defender de não cometer um círculo quando diz que temos a certeza de que as coisas que concebemos clara e distintamente são verdadeiras porque Deus é ou existe. Pois só podemos ter a certeza de que Deus é porque concebemos isso muito clara e distintamente; por isso, antes que seja assegurada a existência de Deus, devemos ter certeza de que todas as coisas que concebemos clara e distintamente são todas verdadeiras ${ }^{4}$.

A resposta a essa objeção do "círculo" foi dada por Descartes na Quartas Respostas onde ele diz:

\footnotetext{
${ }^{1}$ BEYSSADE, Jean-Marie. Sobre o Círculo Cartesiano.In: Revista Analytica. Rio de Janeiro, vol.2, n.1, p.1136, 1997a, p.11.

${ }_{2}$ A nossa escolha das Quartas Objeções e Quartas Respostas se deu devido ao fato de serem dirigidas a Descartes por Arnauld, que segundo Beyssade, é quem deu "à dificuldade sua forma acabada, com seu nome agora tradicional de 'círculo', embora a problemática, antes de receber esse nome, tenha sido levantada por Regius, ainda antes da publicação das Meditações seguido por Mersenne quem também levantou essa questão (Cf. BEYSSADE, Jean-Marie. Sobre o Círculo Cartesiano.In: Revista Analytica. Rio de Janeiro, vol.2, n.1, p.11-36, 1997a, p.13). O que quer dizer que o problema do círculo foi apontado e supostamente respondido em outras Objeções e Respostas.

${ }^{3}$ DESCARTES, René. Discurso do Método, As paixões da alma e Meditações Metafísicas. São Paulo: Editora Nova Cultural Ltda. 1999, p. 270.

4 DESCARTES, René. Méditations Métaphysiques: objcetions et réponses suives de quatre Lettres. Chronologie, présentation et bibliographie de Jean-Marie Beyssade et Michelle Beyssade. Paris: Flammarion, 1992, p.337 (tradução nossa).
}

\begin{tabular}{|c|c|c|c|c|c|}
\hline intuitio & $\begin{array}{c}\text { ISSN } \\
1983-4012\end{array}$ & Porto Alegre & Vol.7 $-\mathrm{N}^{\mathrm{o}} .2$ & $\begin{array}{c}\text { Novembro } \\
2014\end{array}$ & p. 122-133 \\
\hline
\end{tabular}


Definitivamente eu já mostrei claramente nas respostas às Segundas Objeções, números 3 e 4 , que eu não cometi a falta que se chama círculo, quando eu disse que temos a certeza de que as coisas concebemos muito clara e distintamente são todas verdadeiras porque Deus é ou existe, e que temos a certeza de que Deus é ou existe apenas porque o concebemos muito clara e distintamente; fazendo uma distinção das coisas que concebemos muito claramente na verdade, com aquelas que lembramos já ter concebido muito claramente. Pois, primeiramente, temos a certeza que Deus existe porque direcionamos nossa atenção para as razões que nos mostram a sua existência; mas, depois disso, basta que nos lembremos de termos concebido uma coisa claramente para ter certeza de que ela é verdadeira: o que não é o suficiente se não soubéssemos que Deus existe e que ele não pode ser enganador ${ }^{5}$.

$\mathrm{O}$ dirigir a atenção às razões que nos mostram a existência de Deus, a quem concebemos clara e distintamente na medida em que nos certificamos - ao menos momentaneamente - de que existimos e de que não estamos sendo enganados por um Deus embusteiro, já é uma prova de que a ameaça de tal enganador, mostra que essa nossa certeza é provisória e que precisamos ser sustentados por algo superior, o que põe fim às investidas deste embusteiro. Logo, Deus existe e percebemos isso quando concebemos algo clara e distintamente. O que precisamos é de uma prova definitiva de sua existência, concebida clara e distintamente apenas quando o cogito se afirma, momentaneamente diante da dúvida. Ou seja, o que Descartes quer dizer é que existem dois tipos de certeza, uma momentânea, ao nível do cogito e outra definitiva, ao nível do Deus veraz, que confirma definitivamente a verdade e que deve ser o fundamento da ciência. É nesta linha de interpretação que Beyssade oferece uma possível solução para o problema do círculo. Por isso, embora não façamos um estudo exaustivo como o problema pede, acreditamos que na Terceira Meditação, encontraremos uma resposta satisfatória, principalmente no que tange à prova do Deus veraz, o que envolve conceitos como representação, causalidade e substância. A interpretação destes conceitos já nos possibilitará uma noção do que seja o fundamento na metafísica cartesiana.

Lembremos que a afirmação da regra geral como requisito para a obtenção da verdade é feita na Terceira Meditação, que segue a afirmação do pensamento como um atributo que pertence ao eu pensante, não podendo, portanto ser separado dele, expresso por Descartes no famoso axioma "Eu sou, eu existo: isto é certo; mas por quanto tempo? Durante todo tempo em que eu penso; pois talvez poderia acontecer que, se eu parasse de pensar, ao mesmo tempo pararia de ser ou de existir" ${ }^{\prime 6}$. Esta

5 DESCARTES, René. Méditations Métaphysiques: objcetions et réponses suives de quatre Lettres. Chronologie, présentation et bibliographie de Jean-Marie Beyssade et Michelle Beyssade. Paris: Flammarion, 1992, p.369 (tradução nossa).

${ }^{6}$ DESCARTES, René. Discurso do Método, As paixões da alma e Meditações Metafísicas. São Paulo: Editora Nova Cultural Ltda. 1999, p. 261. Antes desta passagem, há outra, ainda na Segunda Meditação na qual Descartes diante da dúvida metafísica devido à possibilidade de um Deus enganador, conclui que se é enganado é porque existe, mesmo sendo enganado será algo enquanto pensar ser alguma coisa. Desta forma conclui que a proposição "eu sou, eu existo, é obrigatoriamente verdadeira todas as vezes que a enuncio ou que a concebo em meu espírito" (DESCARTES, René. Discurso do Método, As paixões da alma e Meditações Metafísicas. São Paulo: Editora Nova Cultural Ltda. 1999, p.258). O cogito é uma certeza, por sinal a única que, ainda que titubeie, permanece diante das investidas da dúvida metafísica (Deus enganador) e será reafirmada diante da certeza metafísica (Deus veraz). Isto é importante para uma compreensão da razão como fundamento da

\begin{tabular}{|c|c|c|c|c|c|}
\hline intuitio & $\begin{array}{c}\text { ISSN } \\
1983-4012\end{array}$ & Porto Alegre & Vol.7 - No.2 & $\begin{array}{c}\text { Novembro } \\
2014\end{array}$ & p. 122-133 \\
\hline
\end{tabular}


afirmação é feita na Segunda Meditação, onde Descartes também, comparando tal conhecimento de si mesmo com a imaginação, que por sinal é também um modo de ser do eu pensante, alerta para que se desvie o espírito de conceber-se ao modo da imaginação, para que possa reconhecer claramente sua natureza ${ }^{7}$. Com isso Descartes demonstra que o cogito possui vários modos de ser, ele quer, sente, imagina e pensa. Dentre todos estes, o último modo é o que lhe permite chegar à verdade sobre si mesmo e sobre o que lhe seja um possível objeto exterior através da representação, que é um aspecto essencial do ato do pensamento ${ }^{8}$. Ou seja, o cogito como uma primeira evidência clara e distinta, atingida pelo pensamento é exposto na Segunda Meditação e retomado na Terceira Meditação como regra geral para se conceber as coisas clara e distintamente, o que permite que sejam verdadeiras.

O eu pensante é uma certeza clara e evidente de sua existência como algo que pensa e que é constantemente acossado pela possibilidade da dúvida, mediante um possível Deus enganador. Ou seja, mesmo sendo uma verdade clara e evidente, o cogito precisa de uma certeza que garanta a permanência de sua existência. Esta certeza tem que eliminar a dúvida metafísica sugerida por um possível Deus enganador, o que somente pode ser o seu oposto, um Deus veraz. É o que Descartes se incumbe de provar na Terceira Meditação. Nesta inicia-se um processo de submissão do Deus enganador ao cogito, o qual vai ganhando autonomia em relação a esse possível algoz. A certeza do eu pensante diante das coisas que concebe clara e distintamente ganha mais força, de modo que o Deus enganador é, de certa maneira, ignorado em função da afirmação da existência do cogito. É o que quer dizer Descartes quando afirma "engane-me quem puder; mesmo assim, nunca poderá fazer que eu nada seja enquanto pensar que sou algo" . O Deus enganador começa a perder a força ameaçadora que tinha, com isso reforça-se a afirmação do cogito, mediante o qual se pode chegar à prova da existência de um Deus veraz. Posta em dúvida a existência de um Deus embusteiro, mediante uma opinião ainda “frágil”, Descartes diz que "para poder afastá-la totalmente, devo analisar se existe um Deus, tão logo surja a oportunidade; e, se concluir que existe um, devo também analisar se Ele pode ser embusteiro" ${ }^{\prime 10}$. Em outras palavras, o Deus embusteiro representa a dúvida universalizada, do mesmo modo que o Deus veraz representa a certeza absoluta. Entretanto, ambos, dúvida e certeza, são antes razões para duvidar e razões para acreditar, e, portanto, nunca dizem respeito a um objeto ou a um juízo sobre um objeto; "não é uma propriedade; é sempre uma relação entre dois elementos no

metafísica cartesiana, como veremos a seguir. O eu pensante é uma certeza que precisa ser reafirmada diante da dúvida, que somente cessa diante da certeza metafísica, mediante a qual se estabelece a verdade da ciência.

${ }^{7}$ Cf. DESCARTES, René. Discurso do Método, As paixões da alma e Meditações Metafísicas. São Paulo: Editora Nova Cultural Ltda. 1999, p. 262.

${ }^{8}$ Cf. ROCHA, Ethel Menezes. O Conceito de Realidade Objetiva na Terceira Meditação de Descartes. In: Revista Analytica. Rio de Janeiro, vol.2, n.2, p.203-218, 1997, p. 209.

${ }^{9}$ DESCARTES, René. Discurso do Método, As paixões da alma e Meditações Metafísicas. São Paulo: Editora Nova Cultural Ltda. 1999, p. 271.

${ }^{10}$ DESCARTES, René. Discurso do Método, As paixões da alma e Meditações Metafísicas. São Paulo: Editora Nova Cultural Ltda. 1999, p. 271.

\begin{tabular}{|c|c|l|l|l|l|}
\hline intuitio & $\begin{array}{c}\text { ISSN } \\
1983-4012\end{array}$ & Porto Alegre & Vol.7- $\mathrm{N}^{\mathrm{o}} .2$ & $\begin{array}{c}\text { Novembro } \\
2014\end{array}$ & p. 122-133 \\
\hline
\end{tabular}


interior de nosso conhecimento, entre uma razão para acreditar e uma razão para duvidar" ${ }^{\text {"1 }}$. O que Descartes se propõe é provar, primeiramente a existência objetiva de um Deus e depois se é verdadeiro ou enganador e assim, certificando-se da existência de um Deus veraz, eliminar a dúvida mediante a certeza.

Nesta demonstração da existência de Deus, primeiramente Descartes faz uma exposição das ideias como provenientes, todas elas do cogito enquanto eu pensante, exceto a idéia de infinitude, que só pode ser uma ideia de uma realidade exterior ao cogito dada a sua finitude. A autonomia da razão encontra seu limite na ideia de Deus, como seu criador e que, embora seja externo ao cogito, ou seja, possui uma realidade objetiva necessária, infunde a ideia do infinito no eu pensante. Somente assim ele, que é finito, pode ter uma ideia do que é infinito e externo a ele.

Ao buscar a prova da existência de Deus, iniciando pelas ideias, Descartes parte do pensamento e de seus vários modos, dos quais a representação é o que se destaca, por ser um modo fundamental do pensamento, por meio do qual se pensa na ideia de si mesmo, dos possíveis objetos externos e de Deus. Todas as ideias têm primeiramente sua realidade formal e objetiva ${ }^{12}$ no cogito, que é afirmado através do pensamento e de seu modo fundamental, a representação. Esta torna possível a elaboração mental da imagem das coisas, resultando uma ideia, que, considerada nela mesma, ou seja, enquanto relacionada ao seu objeto próprio, percebido pelo pensamento enquanto representação, jamais pode ser falsa ${ }^{13}$. A representação é este ato do pensamento em que, diante de um objeto diferente e externo ao cogito, elabora sua ideia formal e objetiva de maneira interna, a partir de si mesmo. De acordo com o grau de realidade da ideia comparada ao objeto representado, se tem uma ideia clara e distinta de tal objeto, como um possível objeto externo ao pensamento.

Para Descartes, o pensamento é o que garante a existência do cogito, o qual é dado primeiramente como uma intuição ${ }^{14}$, a representação como modo do pensamento é o fundamento do conteúdo formal e objetivo das ideias, que remetem a possíveis objetos externos, os quais primeiramente existem no pensamento. Neste caso, a representação é uma atividade do pensamento sobre si mesmo, onde já contém a realidade formal e a realidade objetiva da ideia de um possível objeto externo a ele. O que descarta a possibilidade de uma emissão de juízo sobre um objeto exterior e que é percebido pelos sentidos. "O principal erro e o mais normal que se pode encontrar consiste em que eu julgue que as ideias que se encontram em mim são semelhantes ou conformes às coisas que se

\footnotetext{
${ }^{11}$ BEYSSADE, Jean-Marie. Sobre o Círculo Cartesiano.In: Revista Analytica. Rio de Janeiro, vol.2, n.1, p.1136, 1997a, p. 22.

${ }^{12}$ Para Descartes, a realidade formal da representação é o ato específico do pensamento que é o de representar. Enquanto que a realidade objetiva é o aspecto essencial desse ato: a determinação de algo como distinto, fora da mente (Cf. ROCHA, Ethel Menezes. O Conceito de Realidade Objetiva na Terceira Meditação de Descartes. In: Revista Analytica. Rio de Janeiro, vol.2, n.2, p.203-218, 1997, p. 213).

${ }^{13}$ Cf. DESCARTES, René. Discurso do Método, As paixões da alma e Meditações Metafísicas. São Paulo: Editora Nova Cultural Ltda. 1999, p. 272.

14 Cf. GUIMARÃES, João Antônio Ferrer. A noção cartesiana de subjetividade. [Tese (Doutorado)] Universidade Federal de São Carlos, 2012. São Carlos: UFSCar, 2012, pp.47-48.

\begin{tabular}{|c|c|c|c|c|c|}
\hline intuitio & $\begin{array}{c}\text { ISSN } \\
1983-4012\end{array}$ & Porto Alegre & Vol.7 - N .2 & $\begin{array}{c}\text { Novembro } \\
2014\end{array}$ & p. 122-133 \\
\hline
\end{tabular}
}


situam fora de mim" ${ }^{\prime 15}$. A intencionalidade da representação não consiste na existência independente de seu conteúdo representativo, de modo que seja possível uma relação de um sujeito pensante que apreende um objeto externo a ele e que tem realidade própria. $\mathrm{O}$ que ocorre é que tanto a realidade formal quanto a realidade objetiva de uma ideia, enquanto conteúdo da representação têm uma relação imediata com esta ${ }^{16}$. Descartes inicia a prova da existência de Deus devido a possibilidade de que haja um deus enganador, o que significa a dúvida universalizada. Na prova da existência de Deus, em suas várias razões particulares, tal dúvida deve ser levada em conta. Do contrário, o filósofo cairia em contradição. O que se pretende com a prova da existência de Deus através de seus efeitos é afirmar a autonomia da razão que garante por si só chegar a um fundamento metafísico absoluto para a ciência. Se não há razão para duvidar, não há razão para se errar, e tal fundamento absoluto não se faz necessário. Ou seja, a razão não acessa diretamente a multiplicidade dos entes do mundo, a realidade não é um dado imediatamente percebido pelo sujeito, o que seria muito fácil de evitar o erro. A representação como um caráter fundamental do sujeito pensante, no qual primeiramente se dá a realidade formal e objetiva de possíveis objetos externos, é uma estratégia para a prova da existência de Deus na Terceira Meditação. Ou seja, os objetos externos, devido à representação são possíveis primeiro na mente, depois, de acordo com o grau de realidade de tais objetos representados, são confirmados como claros e distintos. Se fossem diretamente acessados pelo sujeito, não haveria a necessidade de uma fundamentação externa como critério de verdade, o que somente é possível com a descoberta de um Deus veraz ${ }^{17}$.

Neste caráter representativo do pensamento está a possibilidade da prova da existência de um Deus veraz como fundamento externo para a verdade. Entretanto, nesta estratégia, fundamental para a metafísica cartesiana, está contido um elemento novo em relação à metafísica tradicional, que é a ideia de substância finita ${ }^{18}$, sem a qual não se pode provar a existência de Deus como veraz, devido à sua realidade externa ao cogito.

O caráter representativo do pensamento enquanto auto-afirmação do cogito possibilita a Descartes operar uma mudança na metafísica, de modo que a substância passa a ser uma característica do espírito, do corpo e de Deus. A representação, tal como concebida por Descartes, faz com que o objeto externo seja representado como possível primeiro na mente, depois, de acordo com o grau de proximidade e realidade entre a ideia e o objeto representado, se pode afirmá-la como uma ideia clara

\footnotetext{
${ }^{15}$ DESCARTES, René. Discurso do Método, As paixões da alma e Meditações Metafísicas. São Paulo: Editora Nova Cultural Ltda. 1999, p. 271.

${ }^{16}$ Cf. ROCHA, Ethel Menezes. O Conceito de Realidade Objetiva na Terceira Meditação de Descartes. In: Revista Analytica. Rio de Janeiro, vol.2, n.2, p.203-218, 1997, p. 204.

17 Cf. GUIMARÃES, João Antônio Ferrer. A noção cartesiana de subjetividade. [Tese (Doutorado)] Universidade Federal de São Carlos, 2012. São Carlos: UFSCar, 2012, p.105.

${ }^{18}$ Espinoza argumentou contra a concepção do espírito como substância pensante defendendo a tese segundo a qual a noção de substância finita, seja ela pensante ou extensa, é contraditória: não é possível que uma substância seja finita, nem que algo finito possa ser considerado uma substância (Cf. LEVY, Lia. "Eu sou, eu existo: isto é certo; mas por quanto tempo?"'O Tempo, o Eu e os Outros Eus. In: Revista Analytica. Rio de Janeiro, vol.2, n.2, p.161-185,1997b, p. 163).

\begin{tabular}{|c|c|c|c|c|c|}
\hline intuitio & $\begin{array}{c}\text { ISSN } \\
1983-4012\end{array}$ & Porto Alegre & Vol.7 - No.2 & $\begin{array}{c}\text { Novembro } \\
2014\end{array}$ & p. 122-133 \\
\hline
\end{tabular}
}


e distinta. Dentre as ideias claras e distintas das coisas corporais, algumas são provindas da ideia que o cogito tem de si mesmo, como a de substância. O que faz com que tudo que se apresente como externo ao cogito é, de acordo com a metafísica de Descartes, primeiramente uma substância extensa. O que a distingue do cogito é o fato de não pensar. No entanto, ela é uma substância devido ao fato de existir por $\mathrm{si}^{19}$. Ou seja, a partir do caráter representativo do pensamento Descartes identifica três tipos de substâncias: o cogito (espírito), a res extensa (corpo) e Deus. ${ }^{20} \mathrm{O}$ que causará uma mudança em relação à Escolástica, que via Deus como além da substância. Ao contrário, segundo a metafísica de Descartes, não é preciso transgredir a substância para aceder à infinitude. A substância não é por natureza indiferente à infinitude ou à finitude; muito menos ela é por essência substância finita. Há uma espécie de hierarquia, de modo que as substâncias finitas seriam infra-substâncias, devido à sua finitude ${ }^{21}$.

A descoberta da substância finita como algo que é por si mesmo, com a diferença de que a substância pensante caracteriza-se fundamentalmente pela capacidade de representar, enquanto que a substância corpórea não, leva a meditação a concluir que a substância pensante é capaz de ter primeiramente uma ideia formal e objetiva da substância corpórea e seus acidentes, de modo que aquelas ideias que representam as substâncias têm maior grau de realidade objetiva, "participam, por representação, num maior número de graus de ser ou de perfeição do que aquelas que representam

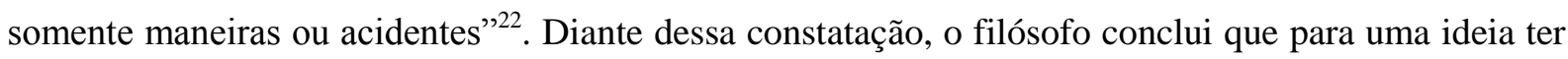
mais realidade formal e objetiva, deve referir-se à substância, a despeito de seus acidentes, nos quais a ideia é representada com menos realidade formal e objetiva. Isto no âmbito das substâncias finitas. Entretanto, se a ideia tem maior realidade formal e objetiva se representada a partir de sua substância, então a ideia pela qual concebemos um Deus infinito, imutável, onisciente, onipotente e criador de todas as coisas que estão fora dele "tem com certeza em si mais realidade objetiva do que aquelas pelas quais as substâncias finitas me são representadas" ${ }^{23}$. Em outros termos, a ideia de Deus possui o mais alto grau de clareza e distinção por ser perfeita e por possuir mais realidade objetiva e formal que

${ }^{19}$ Cf. DESCARTES, René. Discurso do Método, As paixões da alma e Meditações Metafísicas. São Paulo: Editora Nova Cultural Ltda. 1999, pp. 280-281.

${ }^{20}$ Segundo Beyssade, embora seja empregado à alma, ao corpo e a Deus, o termo substância, nas Meditações, não conduz à univocidade "uma vez que a derivação a partir do ego, possível para o que diz respeito a todas as substâncias finitas, é impossível para a idéia da substância infinita, ainda que esta seja a idéia primeira e fundamental da substância. A Segunda Meditação formou, a partir da alma e do pedaço de cera, uma concepção da substância ainda marcada pelas restrições da finitude; a entrada na nova via leva a proceder no outro sentido, a colocar a substância antes do modo e a substância infinita antes das substâncias finitas" (BEYSSADE, JeanMarie. A Teoria Cartesiana da Substância. Equivocidade ou Analogia? In: Revista Analytica. Rio de Janeiro, vol.2, n.2, p.11-36, 1997b, pp.23-24). O que significa que há uma hierarquia entre as substâncias, de modo que, de acordo com Beyssade, sejam análogas e não unívocas.

${ }^{21}$ Cf. BEYSSADE, Jean-Marie. A Teoria Cartesiana da Substância. Equivocidade ou Analogia? In: Revista Analytica. Rio de Janeiro, vol.2, n.2, p.11-36, 1997b, p.23.

22 DESCARTES, René. Discurso do Método, As paixões da alma e Meditações Metafísicas. São Paulo: Editora Nova Cultural Ltda. 1999, p. 276.

${ }^{23}$ DESCARTES, René. Discurso do Método, As paixões da alma e Meditações Metafísicas. São Paulo: Editora Nova Cultural Ltda. 1999, p. 276.

\begin{tabular}{|c|c|c|c|c|c|}
\hline intuitio & $\begin{array}{c}\text { ISSN } \\
1983-4012\end{array}$ & Porto Alegre & Vol.7 $-\mathrm{N}^{\mathrm{o}} .2$ & $\begin{array}{c}\text { Novembro } \\
2014\end{array}$ & p. 122-133 \\
\hline
\end{tabular}


as outras. No entanto, como pode uma ideia de perfeição estar contida no que é menos perfeito? Como pode a ideia do infinito estar contida no finito? Descartes recorre ao princípio de causalidade para confirmar a existência de Deus como substância infinita.

É coisa evidenciada pela razão que deve existir ao menos tanta realidade na causa eficiente e total quanto em seu efeito: porque de onde é que o efeito pode tirar sua realidade a não ser de sua causa? E como poderia esta causa lha comunicar se não a possuísse em si própria?

Daí resulta não apenas que o nada não poderia produzir coisa alguma, mas também que o que é mais perfeito, ou seja, o que contém em si mais realidade não pode ser uma consequência e uma dependência do menos perfeito. [... ${ }^{24}$.

A ideia de Deus remete a uma causa que não é o eu pensante. Sendo este, como acima exposto, uma substância finita, capaz de perceber as ideias como claras e distintas através da representação, de modo que toda ideia de possíveis objetos externos ao pensamento sejam primeiramente elaboradas no âmbito interno, fazendo com que o eu pensante seja sua causa ${ }^{25}$. Ora, neste caso, da ideia de Deus, ela tem uma realidade objetiva e formal externa anterior ao cogito, independente dele, não sendo este sua causa, pelo contrário, ela é a causa do cogito. Sendo que toda ideia refere-se a uma substância, a ideia de Deus refere-se a uma substância infinita, externa ao cogito e, portanto, causa das substâncias finitas. É o que Descartes diz após definir Deus como substância infinita:

[...] é necessário concluir, de tudo o que foi dito antes, que Deus existe; porque, mesmo que a ideia da substância esteja em mim, pelo próprio fato de ser eu uma substância, não teria a ideia de uma substância infinita, eu que sou um ser finito, se ela não tivesse sido colocada em mim por alguma substância que fosse de fato infinita $^{26}$.

Está provada a existência de Deus e o que mais interessa dessa prova é saber que ela é conquistada mediante a razão, ou seja, o eu pensante, através da representação chega à ideia de Deus como substância infinita. O que atormentava o cogito através da dúvida, a saber, a incerteza de quem o criou, da existência ou não de um Deus e de sua bondade ou maldade, agora já não mais o atormenta. Deus existe, é o autor de meu ser e nesta descoberta a dúvida teve um papel fundamental, pois como Descartes mesmo diz, "fosse eu mesmo o autor de meu ser, com certeza não duvidaria de nada, não sentiria mais desejos e, enfim, não me faltaria perfeição alguma" ${ }^{27}$. A finitude da substância pensante, expressa na dúvida constante e na busca de perfeição leva a busca de uma certeza a partir de um ser perfeito, o qual o criou lhe infundiu essa ideia de infinitude e perfeição. E o eu pensante concebe isso

\footnotetext{
${ }^{24}$ DESCARTES, René. Discurso do Método, As paixões da alma e Meditações Metafísicas. São Paulo: Editora Nova Cultural Ltda. 1999, p. 276.

${ }^{25}$ Cf. ROCHA, Ethel Menezes. O Conceito de Realidade Objetiva na Terceira Meditação de Descartes. In: Revista Analytica. Rio de Janeiro, vol.2, n.2, p.203-218, 1997, p. 214.

${ }^{26}$ DESCARTES, René. Discurso do Método, As paixões da alma e Meditações Metafísicas. São Paulo: Editora Nova Cultural Ltda. 1999, p. 281.

${ }^{27}$ DESCARTES, René. Discurso do Método, As paixões da alma e Meditações Metafísicas. São Paulo: Editora Nova Cultural Ltda. 1999, pp. 284-285.

\begin{tabular}{|c|c|c|c|c|c|}
\hline intuitio & $\begin{array}{c}\text { ISSN } \\
1983-4012\end{array}$ & Porto Alegre & Vol.7 - N .2 & $\begin{array}{c}\text { Novembro } \\
2014\end{array}$ & p. 122-133 \\
\hline
\end{tabular}
}


mediante a mesma faculdade que concebe a si mesmo "pelo simples fato de Deus haver-me criado, é muito acreditável que Ele, de alguma forma, me haja produzido à Sua imagem e semelhança e que eu conceba essa semelhança [...] mediante a mesma faculdade pela qual concebo a mim mesmo"28.

Deus, portanto, existe e sua ideia não pode ser falsa, ao contrário é muito clara e distinta, pois contém em si mais realidade objetiva que qualquer outra ${ }^{29}$. E mais, por ser infinito e perfeito, causa de toda ideia de perfeição não pode ser embusteiro, visto que "a razão nos ensina que o embuste depende obrigatoriamente de alguma necessidade ${ }^{\text {"30. }}$.

Com isso acreditamos que extraímos do texto das Meditações Metafísicas a prova da existência de Deus a partir da razão, o que acreditamos ser importante como uma introdução à interpretação do problema do círculo cartesiano, apresentada por Beyssade, da qual o que nos interessa é chegar a uma conclusão do que seja o fundamento na metafísica de Descartes.

Primeiramente gostaríamos de dizer que compartilhamos a interpretação de Guimarães, em relação uma dupla fundamentação na proposta de Beyssade ${ }^{31}$. Esta dupla fundamentação refere-se ao que Beyssade chama de primeira perfectissima cetitudo (o cogito), por meio do qual se obtém as verdades no campo da persuasão, e segunda perfectissima certitudo (Deus), através da qual se obtém a verdade como ciência. A primeira apresenta-se como fundamental para se chegar à segunda, esta, por sua vez, confirma e fundamenta aquela. Ou seja, a prova da existência de Deus, segundo a metafísica cartesiana, deve ser vista como um processo onde todas as razões particulares são encadeadas visando ao objetivo proposto. Não há nenhum problema em partir do cogito para a ideia de Deus, de modo que não incorra em um círculo vicioso. O que há é o fato de o cogito enquanto primeira perfectissima certitudo ser provisório (finito), e Deus enquanto segunda perfectissima certitudo ser definitivo (infinito). Neste argumento de Beyssade, "a linha de defesa pela memória"32 é reinterpretada de maneira que a resposta de Descartes a Arnauld seja esclarecida em relação aos equívocos cometidos pelos seus leitores. Segundo Beyssade, a linha de defesa pela memória comete um erro ao interpretar Deus como um recurso mnemônico. É certo que a resposta de Descartes a Arnauld diz que após nos atermos às razões que mostram a existência de Deus "basta que nos lembremos de termos concebido uma coisa claramente para ter certeza de que ela é verdadeira: o que não é o suficiente se não soubéssemos que Deus existe e que ele não pode ser enganador",33. O que

\footnotetext{
${ }^{28}$ DESCARTES, René. Discurso do Método, As paixões da alma e Meditações Metafísicas. São Paulo: Editora Nova Cultural Ltda. 1999, pp. 288-289.

${ }^{29}$ Cf. DESCARTES, René. Discurso do Método, As paixões da alma e Meditações Metafísicas. São Paulo: Editora Nova Cultural Ltda. 1999, pp. 282

${ }^{30}$ DESCARTES, René. Discurso do Método, As paixões da alma e Meditações Metafísicas. São Paulo: Editora Nova Cultural Ltda. 1999, pp. 289.

${ }^{31}$ Cf. GUIMARÃES, João Antônio Ferrer. A noção cartesiana de subjetividade. [Tese (Doutorado)] Universidade Federal de São Carlos, 2012. São Carlos: UFSCar, 2012, p.141.

${ }^{32}$ BEYSSADE, Jean-Marie. Sobre o Círculo Cartesiano.In: Revista Analytica. Rio de Janeiro, vol.2, n.1, p.1136, 1997a, p. 19.

33 DESCARTES, René. Méditations Métaphysiques: objcetions et réponses suives de quatre Lettres. Chronologie, présentation et bibliographie de Jean-Marie Beyssade et Michelle Beyssade. Paris: Flammarion, 1992, p.369 (tradução nossa).

\begin{tabular}{|c|c|l|l|l|l|}
\hline intuitio & $\begin{array}{c}\text { ISSN } \\
1983-4012\end{array}$ & Porto Alegre & Vol.7 $-\mathrm{N}^{\mathrm{o}} .2$ & $\begin{array}{c}\text { Novembro } \\
2014\end{array}$ & p. 122-133 \\
\hline
\end{tabular}
}


significa um apelo à lembrança para confirmar uma coisa como verdadeira, que por sinal já fora evidente no momento presente em que foi percebida, embora sujeita à dúvida. O que Beyssade chama a atenção para a interpretação desta resposta é para o fato da momentaneidade da evidência enquanto persuasão, ainda sob a ameaça dúvida, que faz com que, mesmo que seja irresistível e nos leve a sua adesão devido à sua evidência, é passível de ser posta em dúvida enquanto não se prove a existência do Deus não-enganador ${ }^{34}$.

Neste sentido se pode dizer que a interpretação de Beyssade sugere uma dupla fundamentação que consiste em uma primeira perfectissima certitudo e uma segunda perfectissima certitudo. A primeira é uma evidência presente denominada de persuasão p que já envolve a afirmação da regra geral RG, segundo a qual tudo o que percebemos clara e distintamente é verdadeiro. No entanto, enquanto não for provada a veracidade divina VD, tanto a RG quanto as proposições singulares $\mathbf{p}$ podem ser colocadas em dúvida. O que faz com que a persuasão inicial precise da prova da veracidade divina para se opor à hipótese do deus enganador. Ao voltar-me para a hipótese do deus enganador, desvio-me da evidência presente, que passa a ser uma evidência no passado, a qual será confirmada depois da prova do Deus veraz. O que quer dizer que sempre que me volto para uma evidência particular (persuasão) não posso duvidar que ela seja verdadeira. No entanto, ao voltar-me para a hipótese de um deus enganador, também não posso deixar de acreditar que ele pode proceder de tal modo que eu me engane. Neste caso, enquanto não for provada a existência e veracidade de Deus, nenhuma persuasão pode ser definitivamente verdadeira (ciência) ${ }^{35}$. Isto nos faz aceitar o cogito enquanto fundamento para a verdade no que tange às proposições particulares enquanto persuasões momentâneas, ainda que sujeitas à dúvida. Veja, o cogito é uma evidência, por sinal a primeira nessa caminhada rumo à fundamentação metafísica da ciência, seu mérito é conduzir a Meditação à veracidade divina, cuja ideia já está infundida nele. O cogito resiste mesmo ameaçado pela dúvida, o que lhe garante a posição de primeira perfectissima certitudo. Pois entre pensamento sobre o deus enganador e sobre cogito, este último se sobressai, de modo que constitui a mais perfeita certeza, pelo fato de que, ao duvidar do cogito, devo pensar nele reafirmando assim sua evidência ${ }^{36}$. E é esta evidência e autonomia do cogito e de suas instâncias que tornam possível a clarificação da ideia do verdadeiro Deus sem precisarem da garantia fornecida pela validação desse Deus veraz ${ }^{37}$. Entretanto, tal autonomia do cogito enquanto primeira perfectissima certitudo encontra-se no âmbito da persuasão, e portanto envolto em obscuridade, o que requer um fundamento mais forte para a ciência. A persuasão precisa estar ligada à ideia verdadeira de Deus para ser digna do nome de ciência. "E só a

${ }^{34}$ Cf. BEYSSADE, Jean-Marie. Sobre o Círculo Cartesiano.In: Revista Analytica. Rio de Janeiro, vol.2, n.1, p.11-36, 1997a, p. 19.

${ }^{35}$ Cf. BEYSSADE, Jean-Marie. Sobre o Círculo Cartesiano.In: Revista Analytica. Rio de Janeiro, vol.2, n.1, p.11-36, 1997a, pp.20-21.

${ }^{36}$ Cf. BEYSSADE, Jean-Marie. Sobre o Círculo Cartesiano.In: Revista Analytica. Rio de Janeiro, vol.2, n.1, p.11-36, 1997a, pp.23-24.

37 Cf. GUIMARÃES, João Antônio Ferrer. A noção cartesiana de subjetividade. [Tese (Doutorado)] Universidade Federal de São Carlos, 2012. São Carlos: UFSCar, 2012, pp.122-123.

\begin{tabular}{|c|c|c|c|c|c|}
\hline intuitio & $\begin{array}{c}\text { ISSN } \\
1983-4012\end{array}$ & Porto Alegre & Vol.7 $-\mathrm{N}^{\mathrm{o}} .2$ & $\begin{array}{c}\text { Novembro } \\
2014\end{array}$ & p. 122-133 \\
\hline
\end{tabular}


segunda forma da perfectissima certitudo, mais perfeita ainda do que a primeira, e que pode e deve se acrescentar a essa última, colocará fim à guerra perpétua do ceticismo, para instaurar a paz de uma 'ciência certa e verdadeira" "38.

Diante do exposto, pode-se dizer que a proposta de Beyssade é a de uma dupla fundamentação, a primeira no âmbito das persuasões, provisórias e nem por isso menos importante devido ao fato de a sua resistência à dúvida conduzir à prova da existência do Deus veraz e, portanto ao segundo fundamento, mais forte; porém ao qual não se chega sem o primeiro. Ainda que a ideia de infinitude seja infundida no eu pensante da mesma forma que a ideia de finitude, o que é importante ressaltar é que ambas são de certa forma possíveis devido ao cogito enquanto intuição imediata. O pensamento é o que garante a existência do $\operatorname{cogito}^{39}$ e é por meio desta que se vai das proposições particulares (persuasão) à verdade absoluta (ciência). O acesso à ideia clara e distinta de Deus mostra que toda verdade depende de Deus, que é incompreensível e não dependente do cogito. Por isso o conhecimento de Deus, alcançado pelo pensamento enquanto modo de ser do cogito é distinto, mas não adequado. Com a metafísica cartesiana, a razão humana, segundo Beyssade, devido à diferença entre o distinto e o adequado, exprime uma abertura para o exterior, de modo que ela interioriza sua relação com o que a ultrapassa e lhe permanece exterior. Diante disso, a conclusão a que Beyssade chega é a de que a solução cartesiana para o problema do círculo vai ao encontro da doutrina da criação das verdades eternas, o que caracteriza o racionalismo cartesiano como um dogmatismo restrito. "Dogmatismo, porque ele fornece a prova de que nossa ciência atinge uma verdade absoluta. Restrito, porque ele mantém a diferença entre distinto e adequado. Nós conhecemos perfeitamente os limites (distinto), nós não esgotamos os conteúdos (adequado)"40.

A razão humana e a ideia de infinito que há nela, faz como que o racionalismo cartesiano não seja encerrado em si mesmo. Ocorre sim, uma interiorização do que lhe é externo. A saída de si mesma para se relacionar com as coisas e ao mesmo tempo mantendo sua coerência interna se dá devido à ideia de infinito, a qual ela entende, mas não domina. Pelo fato de esta mesma ideia estar intrínseca em toda outra ideia, pode-se dizer que na sua clarificação, ela comanda todas as afirmações $^{41}$. Daí a metafísica cartesiana ter, segundo Guimarães, uma dupla fundamentação, embora a tese defendida por ele seja a noção cartesiana de subjetividade, o que o faz buscar elucidar a autonomia da razão a partir da consciência de si. Ele defende a tese de que na auto validação da razão “supera-se a hipótese do Malin Génie e parte-se para a fundamentação da ciência perfeita pela única via possível: a própria razão, cuja autonomia é crucial para garantir uma primeira validação do

\footnotetext{
${ }^{38}$ BEYSSADE, Jean-Marie. Sobre o Círculo Cartesiano.In: Revista Analytica. Rio de Janeiro, vol.2, n.1, p.1136, 1997a, pp.25-26.

${ }^{39}$ Cf. GUIMARÃES, João Antônio Ferrer. A noção cartesiana de subjetividade. [Tese (Doutorado)] Universidade Federal de São Carlos, 2012. São Carlos: UFSCar, 2012, pp. 47-48.

${ }^{40}$ BEYSSADE, Jean-Marie. Sobre o Círculo Cartesiano.In: Revista Analytica. Rio de Janeiro, vol.2, n.1, p.1136, 1997a, p.36.

${ }^{41}$ Cf. BEYSSADE, Jean-Marie. Sobre o Círculo Cartesiano.In: Revista Analytica. Rio de Janeiro, vol.2, n.1, p.11-36, 1997a, p.35.
}

\begin{tabular}{|c|c|l|l|l|l|}
\hline intuitio & $\begin{array}{c}\text { ISSN } \\
1983-4012\end{array}$ & Porto Alegre & Vol.7- $\mathrm{N}^{\circ} .2$ & $\begin{array}{c}\text { Novembro } \\
2014\end{array}$ & p. 122-133 \\
\hline
\end{tabular}


princípio de evidência” ${ }^{42}$. Ou seja, mesmo apontando uma dupla fundamentação na metafísica de Descartes a partir de interpretação de Beyssade, Guimarães enfatiza o papel fundamental da primeira perfectissima certitudo, o seja o cogito e sua auto-validação pelo pensamento.

Para o nosso trabalho o que interessa é que tanto a tese de Beyssade, da primeira e segunda perfectissima certitudo, quanto a interpretação de Guimarães, de uma dupla fundamentação, priorizam o aspecto racional. Toda a metafísica cartesiana, a despeito de o círculo que ela pressupõe ser vicioso ou não, é tributária da metafísica tradicional a qual ela também fez frente, dando um passo adiante, com a descoberta da substância finita. Entretanto, é importante perceber que na interpretação Beyssade o problema do círculo na metafísica de Descartes já fora solucionado por ele nas Respostas às Segundas e Quartas Objeções, embora o argumento que recorre à lembrança tenha sido mal interpretado, não só pelos contemporâneos de Descartes como por grande parte de seus futuros leitores. Parece-nos que a elaboração feita por Beyssade, de uma primeira perfectissima certitudo no âmbito da persuasão e de uma segunda perfectissima certitudo no âmbito da ciência, ao propor uma dupla fundamentação, onde o primeiro fundamento pressupõe e o segundo o confirma, apresenta uma proposta convincente para esta questão.

\section{Referências}

BEYSSADE, Jean-Marie. Sobre o Círculo Cartesiano.In: Revista Analytica. Rio de Janeiro, vol.2, n.1, p.11-36, 1997a.

BEYSSADE, Jean-Marie. A Teoria Cartesiana da Substância. Equivocidade ou Analogia?In: Revista Analytica. Rio de Janeiro, vol.2, n.2, p.11-36, 1997b.

DESCARTES, René. Méditations Métaphysiques: objcetions et réponses suives de quatre Lettres. Chronologie, présentation et bibliographie de Jean-Marie Beyssade et Michelle Beyssade. Paris: Flammarion, 1992.

DESCARTES, René. Discurso do Método, As paixões da alma e Meditações Metafísicas. São Paulo: Editora Nova Cultural Ltda. 1999.

GUIMARÃES, João Antônio Ferrer. A noção cartesiana de subjetividade. [Tese (Doutorado) ]- Universidade Federal de São Carlos, 2012. São Carlos: UFSCar, 2012.

LEVY, Lia. "Eu sou, eu existo: isto é certo; mas por quanto tempo?"O Tempo, o Eu e os Outros Eus. In: Revista Analytica. Rio de Janeiro, vol.2, n.2, p.161-185,1997b.

ROCHA, Ethel Menezes. O Conceito de Realidade Objetiva na Terceira Meditação de Descartes. In: Revista Analytica. Rio de Janeiro, vol.2, n.2, p.203-218, 1997.

Recebido em: 28/04/2014

Aprovado para publicação em: 03/09/2014

${ }^{42}$ GUIMARÃES, João Antônio Ferrer. A noção cartesiana de subjetividade. [Tese (Doutorado)] - Universidade Federal de São Carlos, 2012. São Carlos: UFSCar, 2012, p.111.

\begin{tabular}{|c|c|l|l|l|l|}
\hline intuitio & $\begin{array}{c}\text { ISSN } \\
1983-4012\end{array}$ & Porto Alegre & Vol.7 $-\mathrm{N}^{\mathrm{o}} .2$ & $\begin{array}{c}\text { Novembro } \\
2014\end{array}$ & p. 122-133 \\
\hline
\end{tabular}

